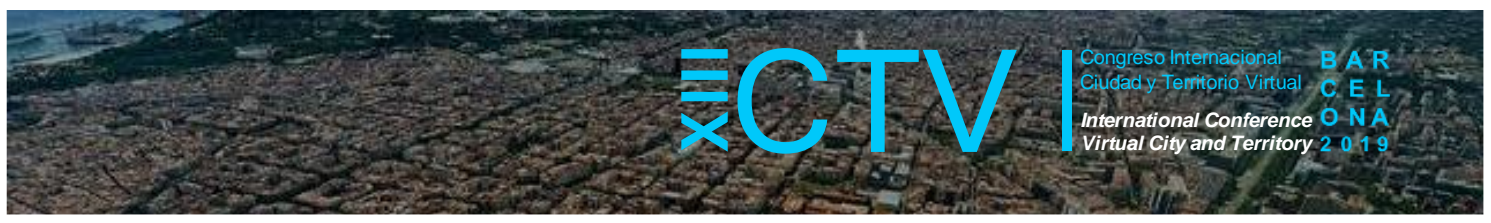

\title{
PROYECTO URBANO CLIMÁTICO EN PALMA DE MALLORCA: EJE ALOMAR - ROSSELLÓ
}

\author{
Architector, Nicolas ${ }^{1 *}$
}

Remisión inicial: 2019-09-16; Remisión definitiva: 2019-10-20; Publicación: 2019-12-21

Citación: Architector, N. (2019). Proyecto urbano climático en Palma de Mallorca: Eje Alomar - Rosselló. En XIII CTV 2019 Proceedings: XIII International Conference on Virtual City and Territory: "Challenges and paradigms of the contemporary city": UPC, Barcelona, October 2-4, 2019. Barcelona: CPSV, 2019, p. 8922. E-ISSN 2604-6512. DOI http://dx.doi.org/10.5821/ctv.8922

\section{Resumen}

Los efectos del cambio climático y la isla de calor urbanos ya no son discutidos en ninguna parte del mundo, y sus consecuencias serán el nuevo paradigma al cual deberemos enfrentarnos en el futuro próximo, de hecho, muchos de estos efectos ya los estamos sufriendo en la actualidad.

A pesar de esto, no se han producido cambios significativos en la metodología del desarrollo de intervenciones urbanas, aun cuando el conocimiento científico es basto y las herramientas para aplicarlo ya se encuentran a nuestra disposición.

Este artículo expone la necesidad de una comprensión metropolitana del entorno urbano, un análisis completo del ámbito de actuación (demográfico, socio-económico, movilidad, normativo, climático y de efectos del cambio climático), el desarrollo de un mapa de comportamiento climático de Climatops, la corroboración de existencia del efecto de isla de calor urbano en la región, el desarrollo de un mapa de recomendaciones climáticas, y el posterior desarrollo de un proyecto urbano climático en el municipio de Palma de Mallorca centrado en tres ejes de actuación: la mejora del verde urbano, generación de espacio público de calidad, y el fomento de una movilidad más sostenible.

Además, se someterá al proyecto a simulaciones climáticas para determinar y cuantificar los efectos que tendrá en el comportamiento climático local, así también para verificar su contribución como mitigador de la isla de calor urbana y los efectos del cambio climático.

\begin{abstract}
Climate change and urban heat island effects are no longer discussed anywhere, and its consequences will be the new paradigm with which we will face in the near future, in fact, we are suffering many of these effects in the present.

Even though we already have the scientific knowledge and the right tools, there weren't significant changes in the methodology of urban developments.

his article exposes the need for a metropolitan understanding of the urban environment, a complete analysis of the area (demographic, socio-economic, mobility, regulatory, climatic and the effects of climate change), the development of a climate behavior map of Climatops, the corroboration of the existence of an urban heat island effect in the region, the development of a map of climate recommendations, and the subsequent development of an urban climate project in the municipality of Palma de Mallorca focused on three areas of action: the improvement of urban green, generation of quality public space, and the promotion of more sustainable mobility.
\end{abstract}

In addition, the project will be subjected to climate simulations to determine and quantify the effects it will have on local climate behavior, as well as to verify its contribution as a mitigator of the urban heat island and climate change effects.

Palabras Clave: cambio climático; sostenibilidad; climatopes; proyecto urbano

Key words: climate change; sustainability; climatopes; urban planning

1 Arquitecto y Máster en Planificación Urbana y Sostenibilidad. Universitat Politécnica de Catalunya, https://orcid.org/0000-0003-3807-960X. *Correo de contacto: narchitector@gmail.com 


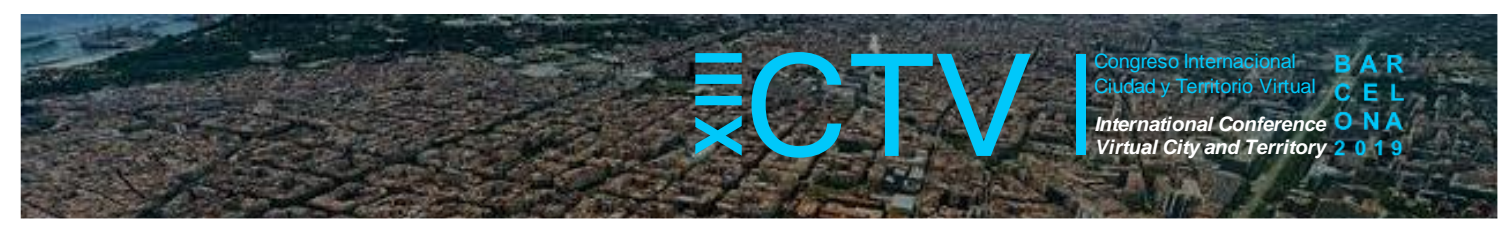

\section{Introducción}

Es inequívoco que el calentamiento en el sistema climático es una realidad, y que la principal contribución al forzamiento radiativo total proviene del aumento en la concentración de $\mathrm{CO} 2$ en la atmósfera debido a la contaminación antropogénica desde la segunda mitad del siglo XVIII.

Cada uno de los tres últimos decenios ha sido sucesivamente más cálido en la superficie de la tierra que cualquier decenio anterior desde 1850, generando que los glaciares y los mantos de hielo de Groenlandia y la Antártida pierdan masa progresivamente y continúen reduciéndose en extensión, a la vez que la temperatura oceánica aumenta.

Las concentraciones de dióxido de carbono han aumentado en un $30 \%$ desde la era preindustrial debido, en primer lugar, a las emisiones derivadas de los combustibles fósiles y, en segundo lugar, a las emisiones netas derivadas del cambio de suelo².

Incluso si se lograra hoy mismo un escenario climático de cero emisiones, la temperatura media global y el nivel de mar seguirían aumentando debido a la inercia térmica oceánica ${ }^{3}$.

Es necesario reducir de forma sustancial y sostenida las emisiones de gases de efecto invernadero en corto plazo para evitar que las consecuencias sean mayores, ya que los escenarios de Representative Concentration Pathways (RCP) más esperanzadores han sido ya superados, y los más peligrosos parecen ser cada vez más certeros, por lo cual deberemos amoldar nuestras ciudades para poder resistir las inclemencias climáticas futuras. Es por eso que en la actualidad se utilizan las terminologías "mitigación" y "adaptación" al cambio climático, y la planificación urbana cumple un papel principal en estas cuestiones.

Este trabajo se desarrolla sobre Palma de Mallorca y su área metropolitana, un territorio cuya economía está basada el turismo de verano, con altos índices de emisiones, un caos vehicular de los más altos del mundo y con una estructura monocéntrica encabezada por el municipio de Palma de Mallorca.

Las proyecciones climáticas para esta región pronostican en finales de siglo aumentos de hasta $6^{\circ} \mathrm{C}$ de temperatura media anual, aumento del $50 \%$ en cantidad de días cálidos y 20 días de aumento de las olas de calor, así como también una disminución en cantidad de días de lluvia, un 25\% menos de precipitación anual, disminución de hasta un 20\% de la evapotranspiración y un aumento de más de un metro del nivel del mar según los escenarios menos alentadores ${ }^{4}$. Este escenario de desertificación tendrá efectos muy dañinos en la salud de la población, el entramado económico-productivo, el turismo y las condiciones de vida de la población local y turista.

Es por eso que las administraciones locales han comenzado a desarrollar iniciativas para adaptarse a estos escenarios con la aprobación de la Ley de Cambio Climático, y algunos pocos proyectos de pacificación vehicular y regeneración de verde urbano que aún no son suficientes como respuesta a los inconvenientes que vaticinan las proyecciones climáticas.

\footnotetext{
2 IPCC AR5, 2014

${ }^{3}$ T.M.L. Wigley, 2005.

${ }^{4}$ AEMET, 2014.
} 


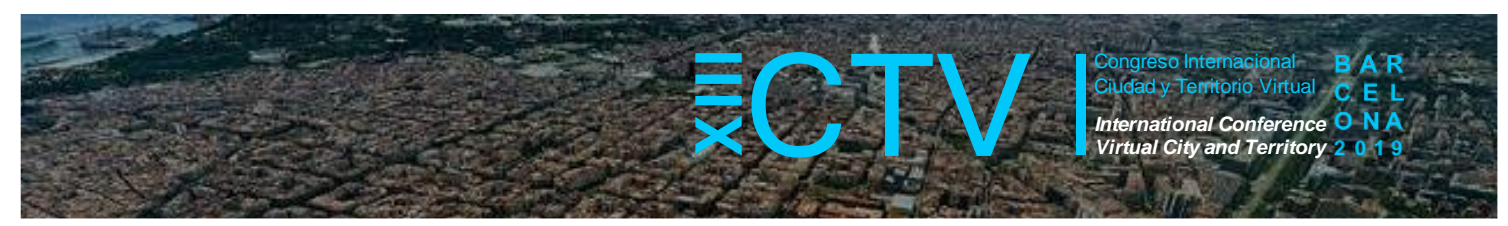

Es necesario profundizar el accionar y realmente migrar hacia una planificación centrada en el análisis climatológico y adaptar los centros urbanos a los desastres climáticos que nos depara el futuro.

Este trabajo analiza el entramado socio-económico, climático y de movilidad del Área Metropolitana de Palma de Mallorca, junto a un análisis climático a partir de imágenes satelitales obtenidas a partir de Landsat-8, Modis 2 y Sentinel 2.0 y utilizando Sistemas de Información Geográfica. Luego realiza un mapa climático de climatopes en dos escalas de análisis (metropolitana e intermedia) con sus correspondientes recomendaciones climáticas evidenciando y cuantificando el efecto Isla de Calor Urbana en la región, para finalmente aportar un proyecto urbanístico sobre el eje formado por las avenidas Gabriel Alomar y Alexandre Rosselló que estará centrado en la rehabilitación climática y del verde urbano, el reordenamiento de la vía pública, el embellecimiento del espacio público y la pacificación del tráfico motorizado, trazando objetivos basados en los ejes de sostenibilidad, salud, movilidad y social.

Finalmente, el proyecto cuenta también con la contrastación de los efectos climáticos que demuestren y cuantifiquen la contribución de la intervención a mitigar los efectos del cambio climático y la isla de calor urbana.

\section{Determinación de Área Metropolitana}

Los ámbitos de estudio en los cuales desarrollaremos este trabajo serán el Municipio de Palma de Mallorca y su Área Metropolitana, es por eso que para comenzar deberemos expresar cual es nuestro entendimiento sobre esta influencia a escala metropolitana del Municipio de Palma de Mallorca.

En la actualidad no existe ningún órgano administrativo local que presente una consideración oficial con respecto a este tópico, tampoco existen figuras gubernamentales o de gestión de escala metropolitana, como si existen en Barcelona con la figura de AMB.

Para la determinación del Área Metropolitana de Palma de Mallorca fue utilizado como base la metodología a partir del cálculo de los valores de interacción municipal a partir de la matriz de flujos residencia/trabajo, reconociendo a los nodos de empleo como vertebradores del sistema urbano.

$$
\begin{gathered}
V v_{i j}=\frac{F_{i j}^{2}}{P O R_{i} \cdot \mathrm{LTL}_{j}}+\frac{F_{j i}^{2}}{P O R_{j} \cdot \mathrm{LTL}_{i}} \\
\text { Fuente: Roca, J. et al (2011) }
\end{gathered}
$$

Donde, $\mathrm{VI}$ es valor de interacción entre los municipios $i$ y $j, F$ son los flujos de interacción, $P O R$ es la población ocupada existente y $L T L$ los lugares de trabajo localizados ${ }^{5}$. Luego se analizó la interacción entre los proto-sistemas generados para determinar un Área Metropolitana (A partir de ahora "AMPM") con corazón en el municipio de Palma de Mallorca.

\footnotetext{
${ }^{5}$ Metodología empleada por Roca, J. et al (2011).
} 


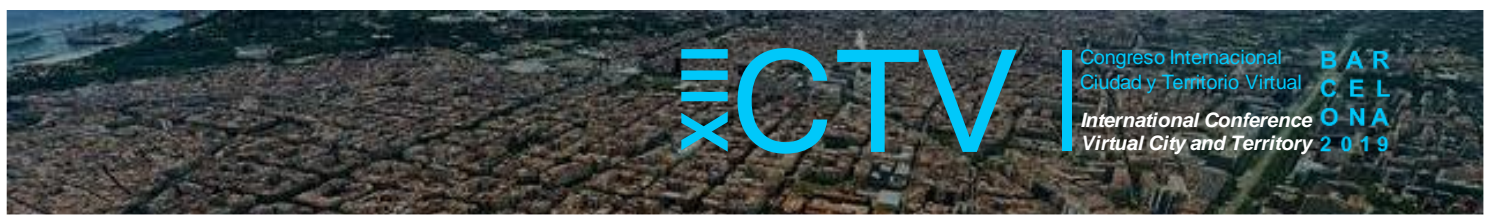

Figura 1. Área Metropolitana de Palma de Mallorca (en azul)

Fuente: Elaboración propia.

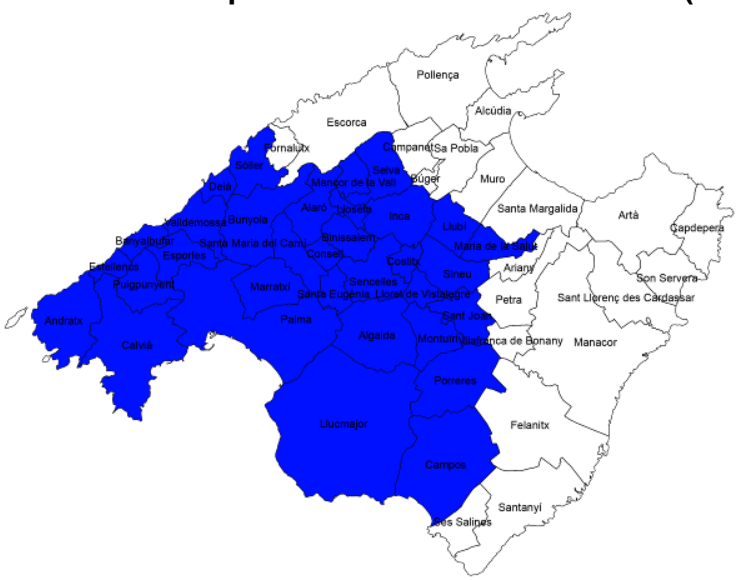

\section{Diagnóstico y análisis de sitio}

Se realizó un exhaustivo análisis histórico, normativo, de crecimiento urbano, demográfico, socioeconómico, climático y turístico del cual las consideraciones más significativas fueron:

\subsection{Análisis demográfico y socioeconómico}

Existe una fuerte centralidad de la región en el municipio de Palma de Mallorca, que aglomera más de la mitad de la población de la isla y es la de mayor densidad, seguida por los municipios linderos de Calvià, Marratxí, Llucmajor, y luego por los subcentros regionales de Inca y Manacor.

Figura 2. Jerarquías municipales según población Figura 3. Densidad poblacional por municipio
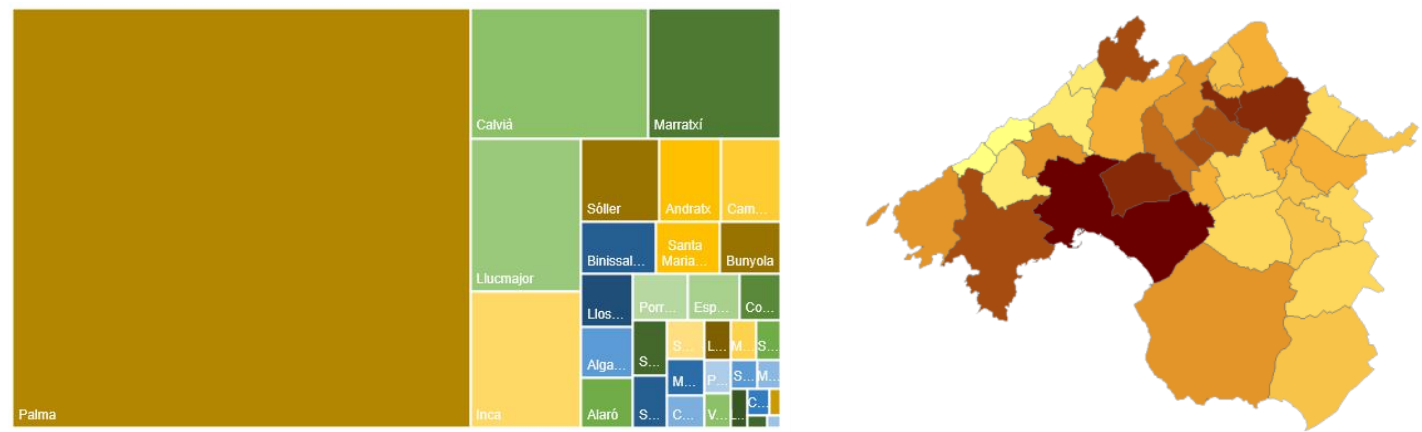

Fuente: Elaboración propia a partir de datos de Revisión del Padrón 2018. IBESTAT.

La región cuenta con grandes porcentajes de población extranjera y de procedencia peninsular debido a que el crecimiento urbano ha sido en las últimas décadas e influenciada por el auge turístico en las Islas Baleares. Se identifican dos sistemas económicos muy diferenciados en AMPM. En primer lugar, se evidencia un sistema costero de gran concentración turística y hotelera que actúan como estructuradores económicos de la región, mientras que en los municipios centrales existe una menor presencia de empresas turísticas y se muestran aumentos en actividades industriales y productivas. Esta distinción entre la costa turística y los municipios centrales se evidencia también en las edades medias municipales, donde la 


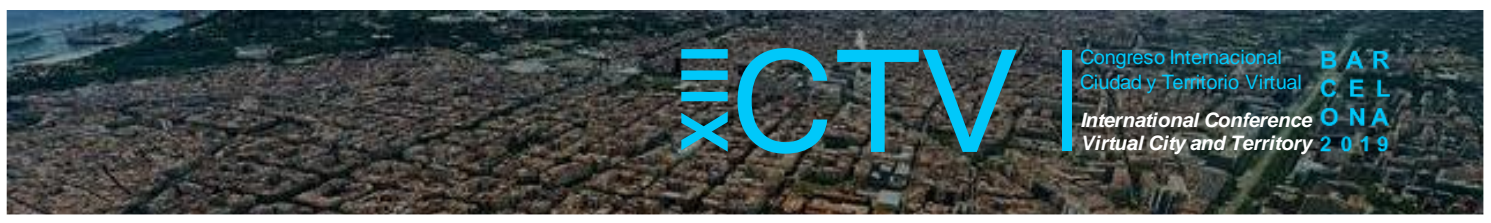

población en edad laboral y los jóvenes tienen mayor presencia en la costa, de mayores oportunidades de trabajo, frente a los municipios centrales que muestran una mayoría de población de edad avanzada.

El turismo es el gran estructurador de la región, registrando ingresos de casi 14 millones de personas durante el pasado $a n ̃ 0^{6}$ con entrada por el puerto y el aeropuerto de Palma de Mallorca, municipio que cuenta con apenas 400.000 residentes. Además, estos ingresos se concentran principalmente en los meses veraniegos debido al turismo de playa.

Figura 4. Índice de Presión Humana en Isla de Mallorca (1997-2018)

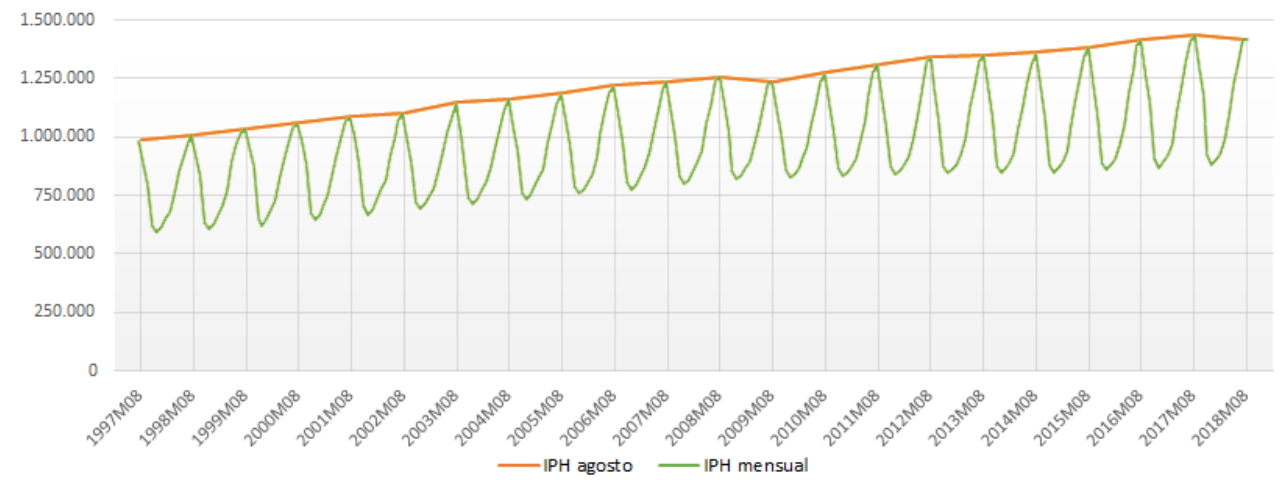

Fuente: Elaboración propia a partir de datos de IBESTAT.

Estos factores, junto con la aparición de plataformas de alojamiento turístico colaborativo como Airbnb, han provocado un aumento en la oferta de alojamiento turístico y en el precio de los alquileres convencionales por la presión inmobiliaria en busca de la renta diferencial que propone el alojamiento turístico.

\subsection{Análisis de movilidad y calidad del aire}

El municipio de Palma de Mallorca se encuentra totalmente desconectado de su Área Metropolitana, esto se debe a una incongruencia en las competencias del planeamiento, que otorgan competencias autonómicas en Transporte, competencia insular en Carreteras, y competencias municipales en Movilidad y transporte colectivo, dificultando cualquier integración supramunicipal en el desarrollo de la movilidad. Es así que, al no existir conexión de transporte público de calidad fuera del municipio de Palma de Mallorca, la opción más elegida por los habitantes es el uso del vehículo privado.

Debido a esto es que Palma de Mallorca muestra índices de 913 automóviles cada 1000 habitantes ${ }^{7}$ y un reparto modal de $55 \%$ de viajes en vehículos privados y sólo un $10 \%$ en transporte público colectivo ${ }^{8}$. Además de la falta de regulación de aparcamientos sobre espacio público como plazas, bulevares y aceras.

Además, el tráfico vehicular es responsable de los mayores índices de ruido por sobre las recomendaciones de la OMS e influye fuertemente en los niveles de contaminación del aire, ya

\footnotetext{
6 INE, 2018

${ }^{7}$ Fuente: INE, IBESTAT. Cifras 2019

${ }^{8}$ GOIB. Conselleria territorio, energía i mobilitat. 2018. Pla Director Sectorial de Mobilitat de les Illes Balears 20192026. Presentación oficial del Resum aprovació inicial.
} 


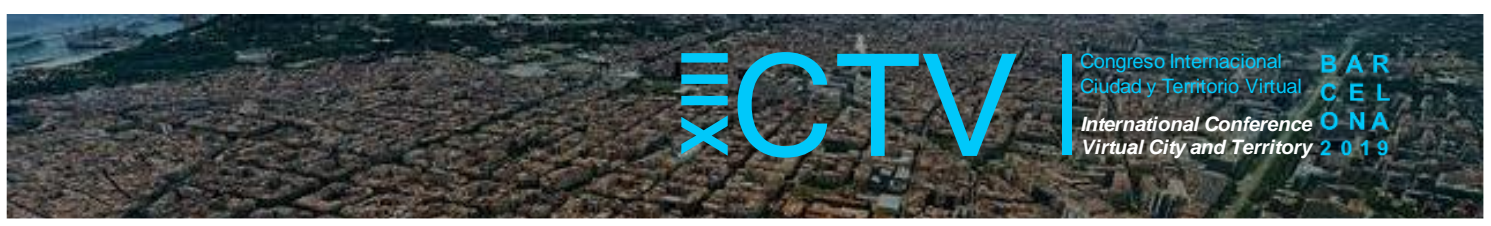

que sólo se observan niveles sobre los índices recomendados en el área urbana de Palma de Mallorca en aquellos contaminantes relacionados con la combustión vehicular (CO, NO2, PM10, PM2.5), salvo el O3, cuyas razones son la acción de la radiación sobre otros contaminantes primarios, y parte del PM10 derivado de las arenas de saharianas. ${ }^{9}$

\subsection{Análisis climático y escenarios del cambio climático}

Actualmente, AMPM tiene un clima cálido y seco en verano, cuando la media de temperatura máxima es superior a los $31^{\circ} \mathrm{C}$, un otoño que acumula la mayor parte de las lluvias anuales, las cuales se precipitan principalmente en la Sierra Tramuntana y alimentan desde allí a las rieras que irrigan toda la isla.

En cuanto a las proyecciones climatológicas por los efectos del cambio climático en la región, Islas Baleares es una de las regiones que se llevará la peor parte. Los modelos muestran aumento de temperaturas máximas y mínimas hasta de $6^{\circ} \mathrm{C}$, aumento de hasta un $50 \%$ en porcentaje de días cálidos, aumento de duración de olas de calor, disminución de cantidad de días con lluvia, disminución de precipitación anual y en verano y un descenso del $20 \%$ en la evapotranspiración, es decir, un panorama de desertificación.

Figura 5. Escenarios futuros de temperatura, precipitación y evapotranspiración en AMPM
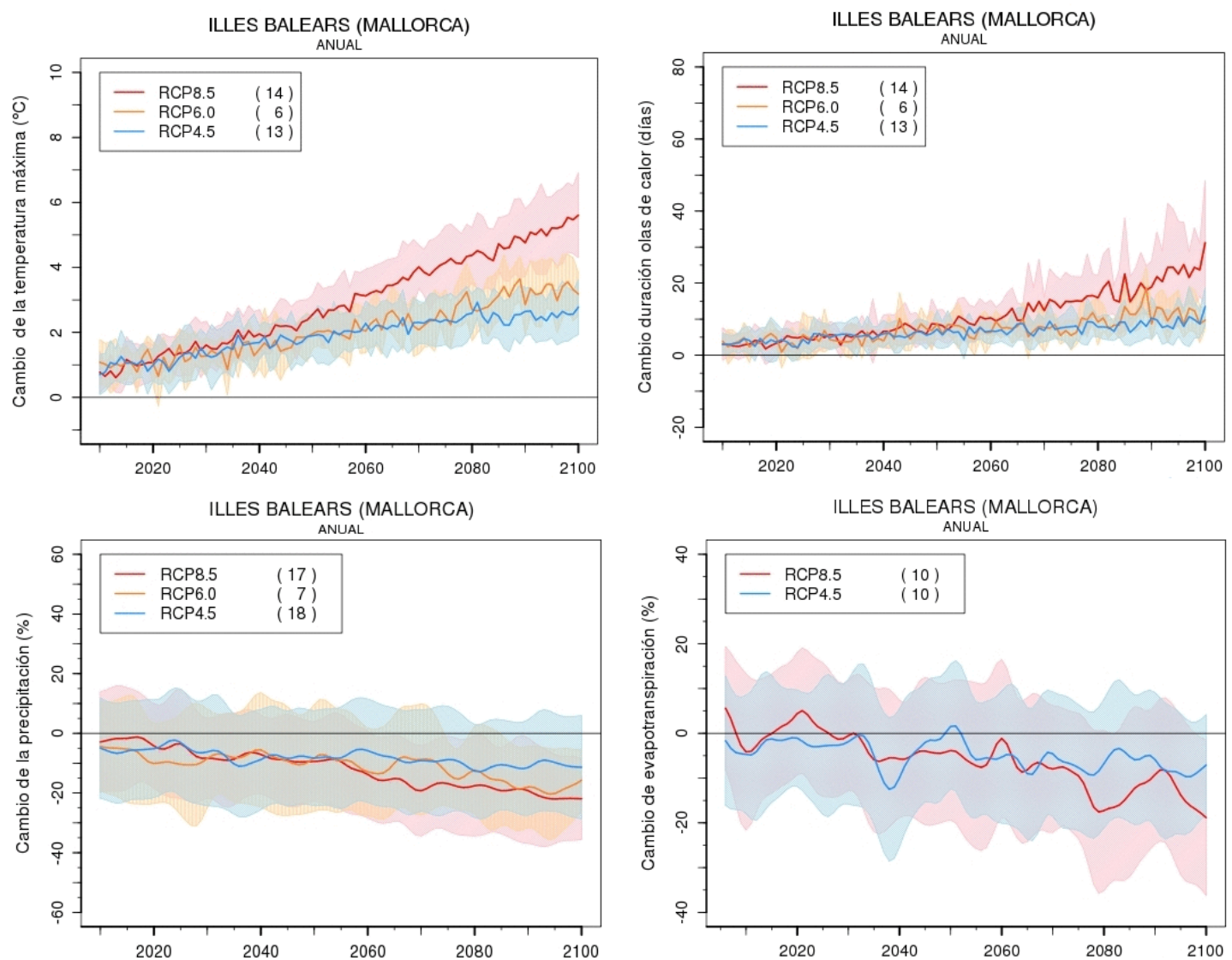

Fuente: Proyecciones climáticas para el siglo XXI. AEMET.

\footnotetext{
${ }^{9}$ Fuente: Mapa Estratégico del Ruido de la aglomeración de Palma de Mallorca. 2005. y AEMET, 2018.
} 


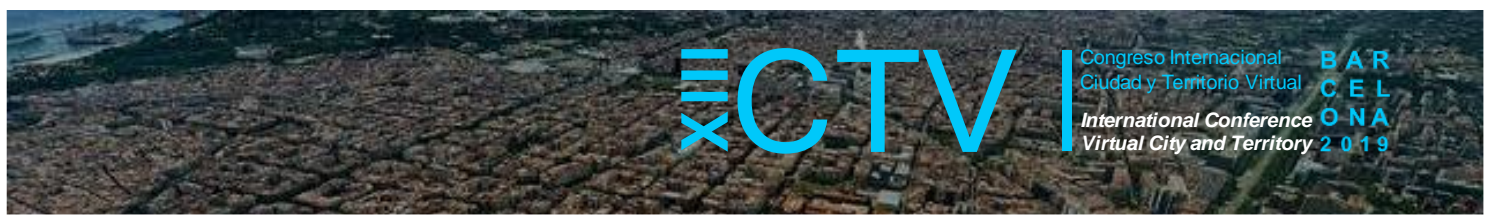

A esto se sumará el aumento del nivel del mar, que según las proyecciones RCP8.5 podrían superar en más de un metro los niveles actuales.

\section{Mapa climático de climatopes}

A partir de imágenes satelitales obtenidas a partir de Landsat 8, Modis 2 (composición de 8 días) y Sentinel 2.0 se han calculado, utilizando software GIS, los siguientes índices para las cuatro estaciones del año: NDVI, LST día, LST noche, diferencia entre LST día y noche, EVI, SAVI, MNDWI. Y junto con las cartografías de Hidrografía, DTM, Corine Land Cover, ortofotos, normativa de planeamiento urbano y de áreas protegidas, se ha realizado un Mapa de Climatopes donde se ha reconocido el comportamiento climático de cada uno de estos sistemas, separando el suelo en: Urbano de densidad alta, urbano de densidad media, urbano de densidad baja, tejido industrial, espacios verdes urbanos y parques, espacios abiertos de baja rigurosidad, áreas forestales de densidad arbórea alta, áreas forestales de densidad arbórea media, áreas arenosas, cuerpos de agua, red férrea y viaria principal, puertos, aeropuertos, áreas de alto riesgo de contaminación.

Tabla 1. Comportamiento climático de los climatopes

\begin{tabular}{|c|c|c|c|c|c|c|}
\hline & \multirow{2}{*}{\multicolumn{4}{|c|}{ Valores de verano }} \\
\hline & & & & & & \\
\hline $\mathrm{N}$ & Climatope & $\%$ de Sup. & LST día media (으) & LST noche media (ㅇ) & Diferencia Temp. (ำ) & NDVI medio \\
\hline 01 & Urbano de densidad alta y traza medieval & $0,99 \%$ & 38,78 & 24,05 & 14,73 & 0,19 \\
\hline 02 & Urbano de densidad media y traza tipo ensanche & $1,19 \%$ & 38,22 & 23,65 & 14,57 & 0,22 \\
\hline 03 & Urbano de densidad baja y traza tipo sprawl & $3,24 \%$ & 36,43 & 22,32 & 14,11 & 0,31 \\
\hline 04 & Tejido industrial & $0,57 \%$ & 41,55 & 21,19 & 20,36 & 0,14 \\
\hline 05 & Espacios verdes urbanos y parques & $0,11 \%$ & 37,66 & 23,28 & 14,38 & 0,33 \\
\hline 06 & Espacios abiertos de baja rugosidad & $55,22 \%$ & 40,25 & 20,29 & 19,96 & 0,30 \\
\hline 07 & Áreas forestales de media densidad & $10,56 \%$ & 35,54 & 20,77 & 14,77 & 0,40 \\
\hline 08 & Áreas forestales de alta densidad & $26,69 \%$ & 33,27 & 20,25 & 13,02 & 0,49 \\
\hline 09 & Áreas arenosas & $0,04 \%$ & 33,86 & 21,12 & 12,74 & 0,11 \\
\hline 10 & Cuerpos de agua interiores (no mar) & $0,23 \%$ & 36,92 & 22,31 & 14,61 & 0,15 \\
\hline 11 & Red viaria principal y vías ferreas & $0,53 \%$ & 40,13 & 21,82 & 18,31 & 0,22 \\
\hline 12 & Puertos & $0,08 \%$ & 34,94 & 22,95 & 11,99 & 0,12 \\
\hline 13 & Aeropuertos & $0,18 \%$ & 39,85 & 22,93 & 16,92 & 0,11 \\
\hline 14 & Áreas de alto riesgo de contaminación & $0,37 \%$ & 39,55 & 21,01 & 18,54 & 0,20 \\
\hline
\end{tabular}

Fuente: Elaboración propia.

De esta forma hemos podido corroborar que el tejido industrial es el más caliente durante el día, pero el de mayor capacidad de enfriamiento junto a los suelos agrícolas de baja rugosidad, también que la vegetación de las áreas forestales provoca que se calienten menos durante el día y se enfríen menos durante la noche. Pero lo más destacado ha sido que los diferentes tejidos urbanos se comportan de maneras muy distintas, el tejido de densidad baja, mayormente Urban Sprawl, se comporta muy similar a las áreas forestales por la gran cantidad de vegetación, el área urbana de densidad media se comporta tomando altas temperaturas durante el día y muestra dificultades para enfriarse durante la noche, pero este fenómeno de incapacidad de enfriamiento nocturno es mayor en el tejido de alta densidad presente en el casco histórico de la ciudad, donde se calienta mucho durante el día y durante la noche es el más cálido. Este factor demuestra la existencia del efecto de Isla de Calor Urbano, y nos permite identificar el sector en el que ocurre.

A partir de esto, se ha elaborado un mapa de recomendaciones para preservar aquellos ecosistemas en peligro, mejorar la conectividad ecológica, establecer límites para el crecimiento urbano sobre ecosistemas vulnerables y favorecer una mejor ventilación. 


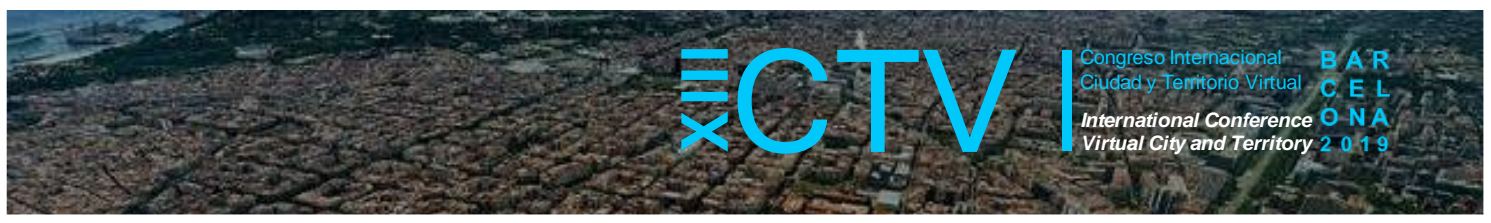

Figura 6. Mapa de Climatopes y mapa de recomendaciones
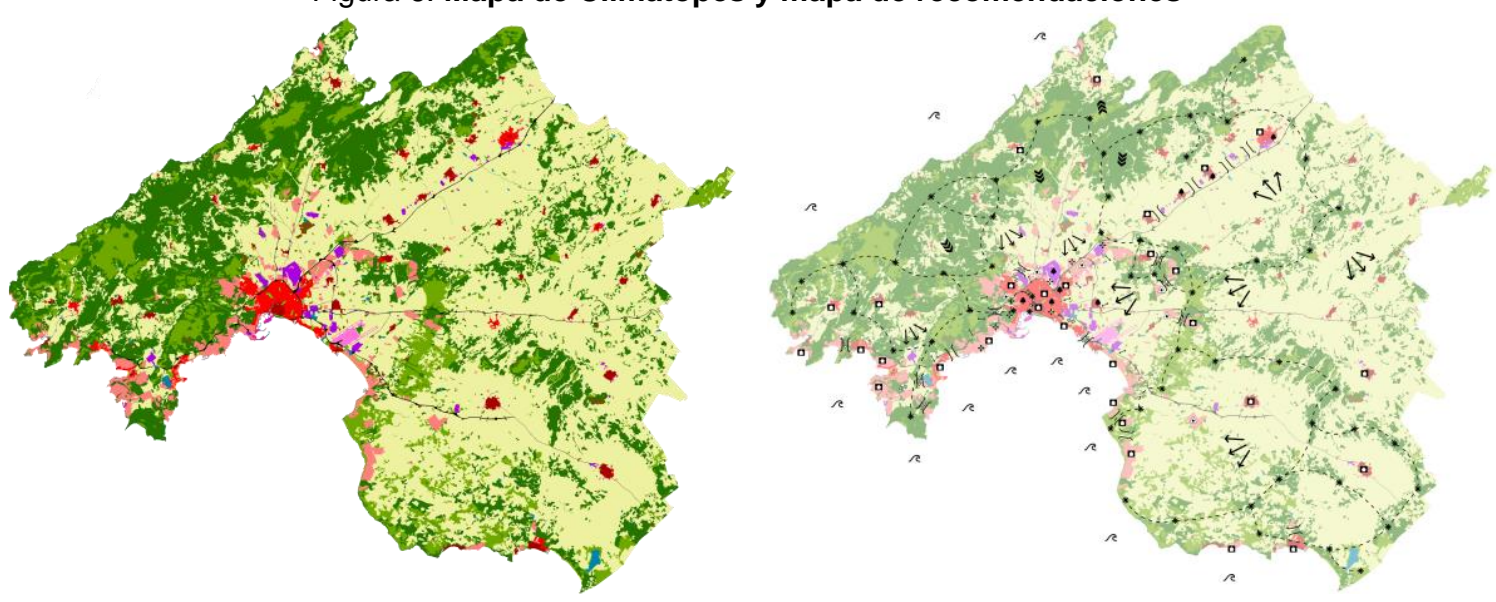

Fuente: Elaboración propia.

\section{Proyecto Urbano Climático: Eje Alomar - Rosselló}

El área elegida para intervenir es el eje de $1500 \mathrm{mt}$ formado por las avenidas Gabriel Alomar y Alexander Rosselló, sobre la traza donde solía estar la muralla medieval, y conecta la Plaza España con el Parque del Pocoyo y el Mar Mediterráneo.

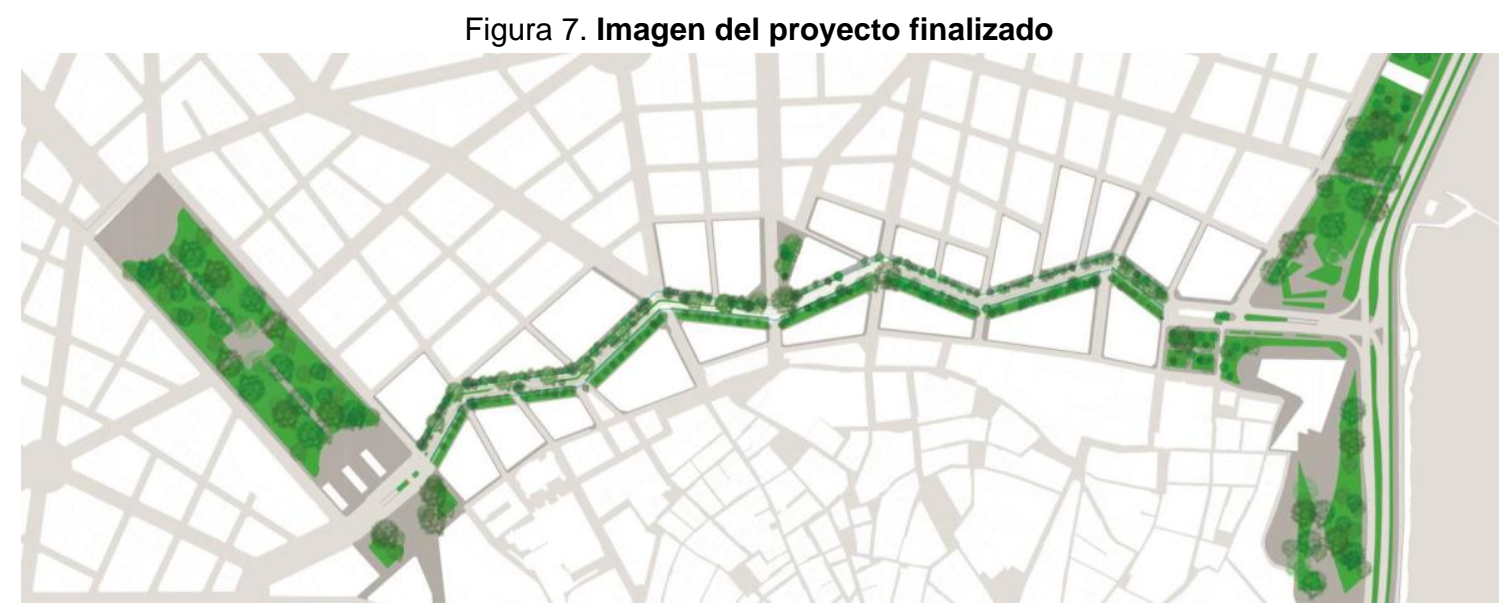

Fuente: Elaboración propia.

El área de intervención se encuentra dentro de la zona más afectada por el efecto Isla de Calor Urbano, se encuentra como límite de dos barrios considerados vulnerables socioeconómicamente, no cuenta con espacio público de calidad, muestra altos índices de congestión vehicular, ruido y contaminantes sobre los valores recomendados por la OMS, cuenta con muchas escuelas y está señalado como un sector prioritario de intervención peatonal en el Plan de Movilidad Urbana Sostenible debido a su intensidad peatonal.

El plan se erigió sobre tres ejes de actuación: La mejora del verde urbano, Generación de espacio público de calidad, y el Fomento de una movilidad más sostenible. 


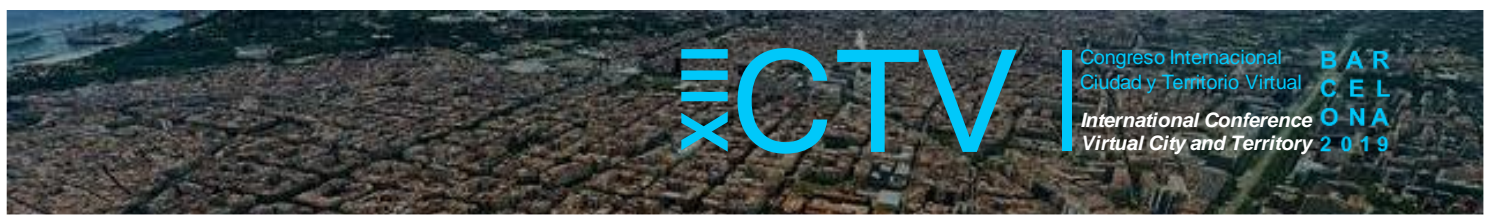

Figura 8. Imagen del proyecto finalizado

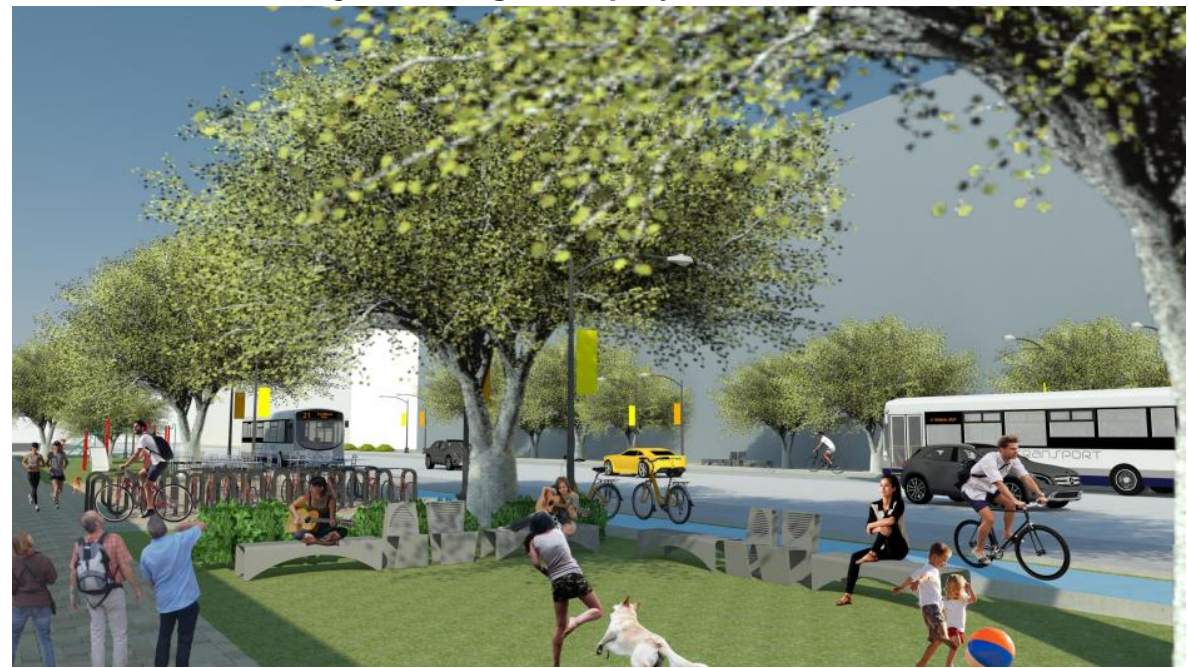

Fuente: Elaboración propia.

\section{$5.1 \quad$ Movilidad}

Actualmente existen hasta nueve carriles para el paso de automóviles sobre el área de proyecto, los automóviles privados estacionan sobre los bulevares, la traza de carril exclusivo para transporte público cubre el $50 \%$ de la vialidad, no existen carriles bici y las aceras de hasta 5 metros de ancho son escasas para los más de 15.000 peatones cada 12 horas $^{10}$.

Figura 9. Sección viaria existente y de proyecto

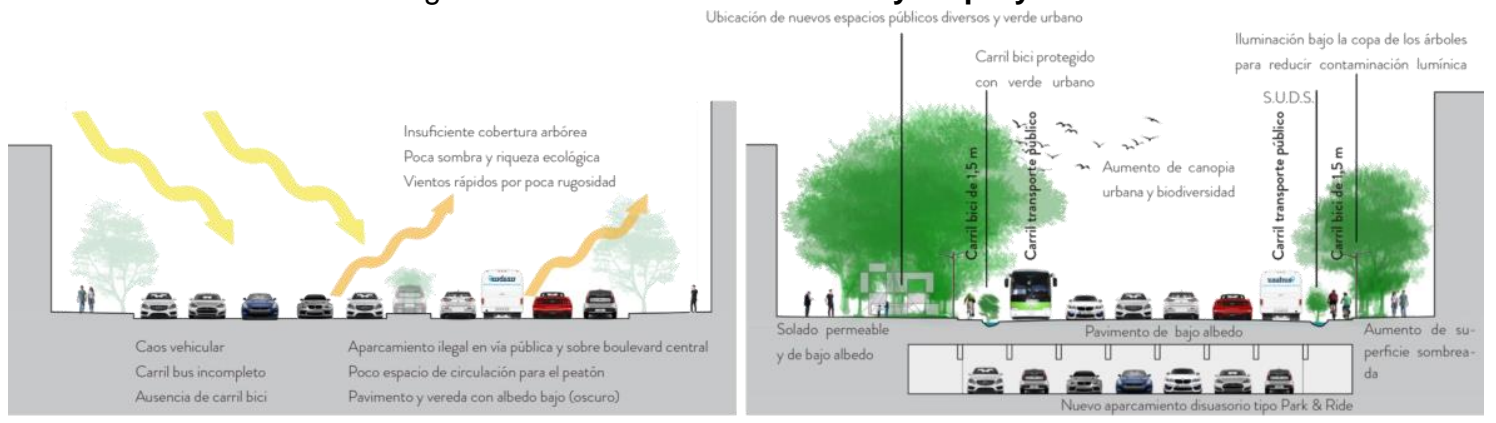

Fuente: Elaboración propia.

Para determinar las nuevas secciones de la vialidad, se tomaron como válidos las directivas tomadas por el Ajuntament de Palma de Mallorca en el Proyecto de Remodelación del Paseo Marítimo, ya que se desea continuar y profundizar en las buenas políticas de pacificación viaria propuestas en este proyecto.

Es por eso que se han quitado carriles dedicados al automóvil privado, se ha completado la traza de carriles exclusivos para transporte público, se agrega carriles bici en ambos sentidos de circulación en la totalidad de la traza y se ha aumentado el transporte público. Además, se han reorganizado las paradas de transporte público en coincidencia con el equipamiento presente en el área y se han agregado aparcamientos disuasorios de Park \& Ride y se añadieron estaciones de la red de bicicletas públicas, ya existente en el municipio.

\footnotetext{
${ }^{10}$ Fuente: Documento diagnóstico del PMUS - Plan de Movilidad Urbana Sostenible.
} 


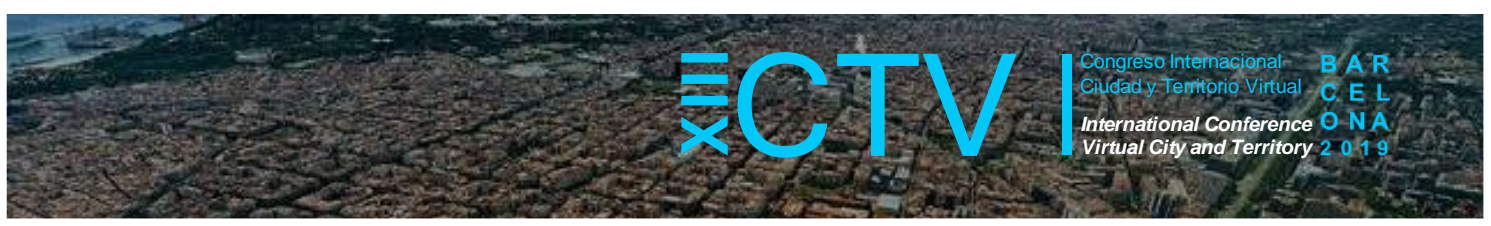

Los carriles bici están proyectados de 1,50mts de ancho y sentido único, para fomentar su uso a partir de ofrecer equipamiento de calidad, estos estarán en ambos sentidos y serán coincidentes con el sentido de tráfico para evitar accidentes, ya que el conductor solo debe ver para un lado antes de doblar en las esquinas. Estos carriles estarán también protegidos con verde urbano para evitar la sensación de peligro en los ciclistas.

\subsection{Conectividad ecológica y verde urbano}

Una de las premisas es generar un conector ecológico entre los parques de los extremos del proyecto, es por eso que se han aumentado las áreas verdes y de vegetación de $1.700 \mathrm{~m}^{2} \mathrm{a}$ $12.800 \mathrm{~m}^{2}$ con el proyecto terminado, y agregado miles de árboles para densificar la canopia y favorecer intercambios genéticos entre las áreas verdes.

Figura 20. Imagen del proyecto finalizado

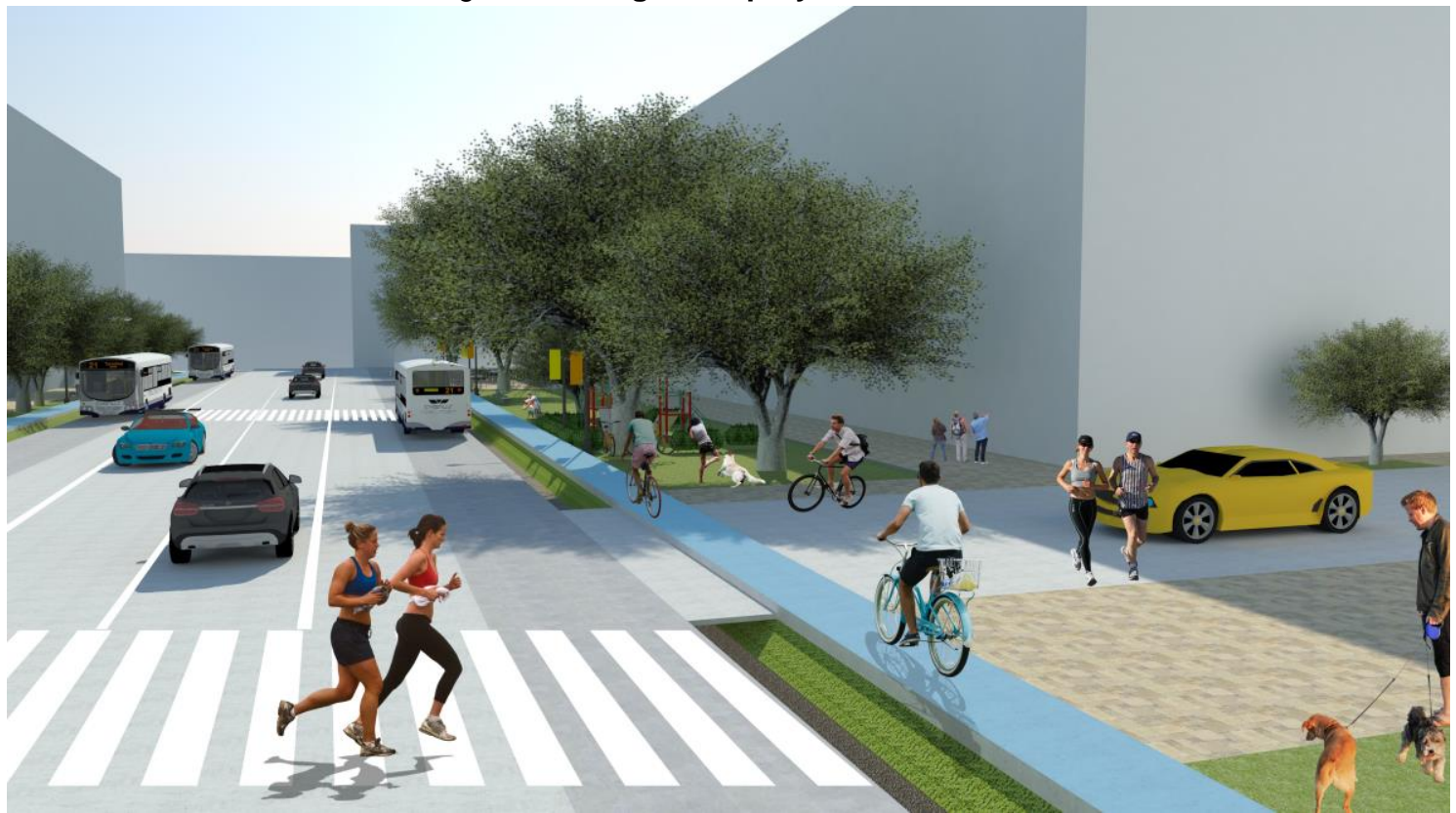

Fuente: Elaboración propia.

\subsection{Espacio público de calidad}

El proyecto otorga mayor espacio peatonal y caminable en ambas aceras, este ha sido repartido teniendo en cuenta el equipamiento existente y las necesidades de la población local. Se han proyectado sectores de reunión vecinal, espacio de juegos para niños, adultos y mascotas, además de la creación de un corredor deportivo con áreas de equipamiento deportivo y zonas de descanso.

Estas áreas están proyectadas para el uso de la población local y para aumentar la actividad barrial y la apropiación del espacio público por los ciudadanos en un espacio que hasta el día de hoy pertenece a los automóviles. 


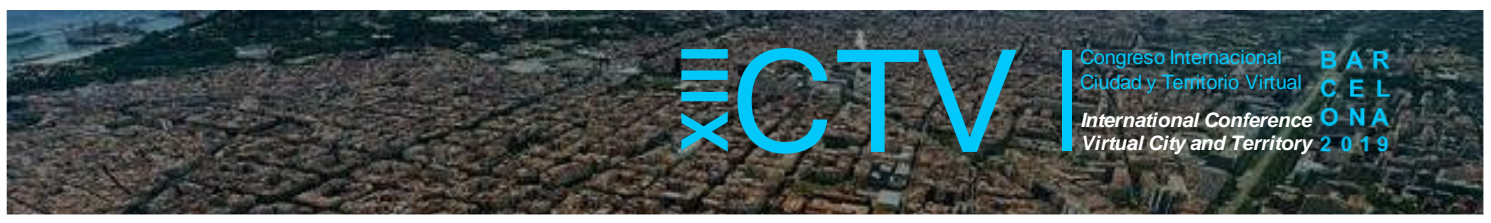

Figura 31. Áreas de uso especializado del espacio público en la traza de proyecto

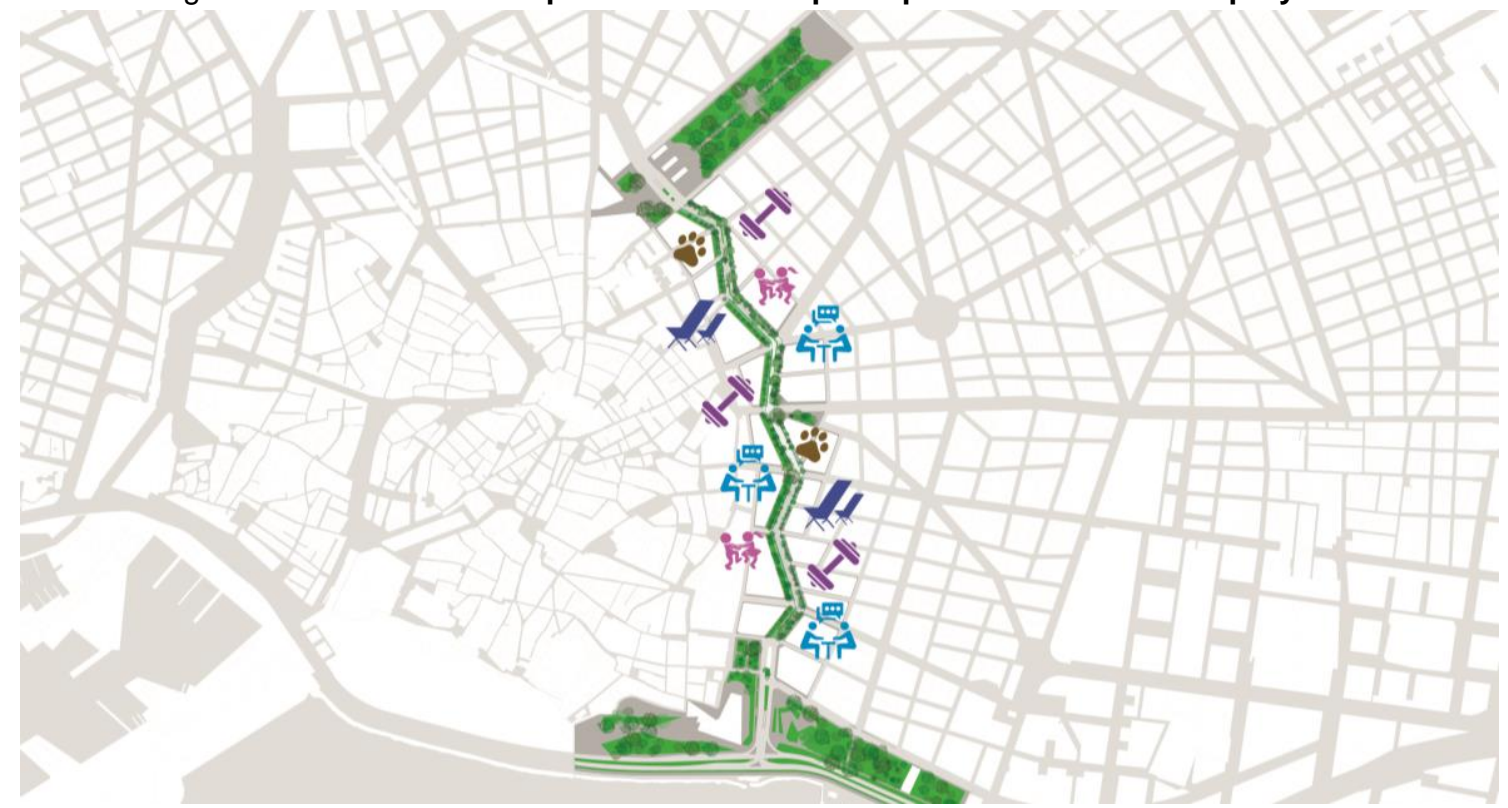

Fuente: Elaboración propia.

De esta forma, el reparto espacial de los usos del área de actuación pasaría, de la situación inicial a la final, según se muestra en la tabla siguiente.

Tabla 2. Reparto espacial existente y de proyecto

\begin{tabular}{lrr}
\hline Reparto espacial & \% de suelo existente & \% de suelo con proyecto terminado \\
\hline Peatonal & $29 \%$ & $\mathbf{4 5 \%}$ \\
\hline Carril bicicleta & $0 \%$ & $8 \%$ \\
\hline Exclusivo transporte público & $8 \%$ & $17 \%$ \\
\hline Vehículos en general & $64 \%$ & $30 \%$ \\
\hline
\end{tabular}

Fuente: Elaboración propia a partir de datos catastrales y ortofotos.

\subsection{Contrastación climática}

Para corroborar el correcto comportamiento climático y verificar los efectos de la intervención a para servir como mitigador de los efectos consecuencia del cambio climático y la isla de calor urbana, se han realizado simulaciones en el software ENVIMET 4.4.3 del escenario existente diurno y nocturno, y del escenario de proyecto terminado diurno y nocturno.

Se modeló un terreno de $250 \times 364$ metros en pixeles de $2 \mathrm{~m} \times 2 \mathrm{~m}$ a partir de un modelado digitalizado del terreno, las alturas fueron asignadas siguiendo los datos catastrales y ortofotos, mientras que el estado actual del arbolado y vegetación fue relevado utilizando Google Street View. Las condiciones climáticas y de viento fueron extraídas del portal de AEMET y asignadas de igual manera a los cuatro escenarios simulados. 


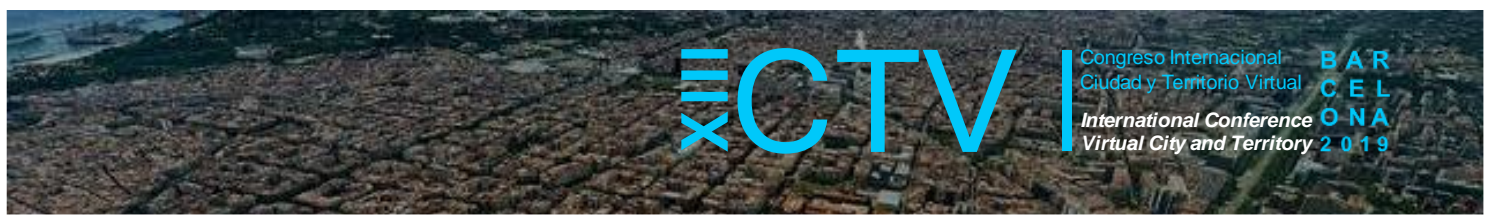

Figura 12. Modelado de superficies en 2D y 3D con temp. de aire. 1ㅇ: Existencias; 2ㅇ: Proyecto
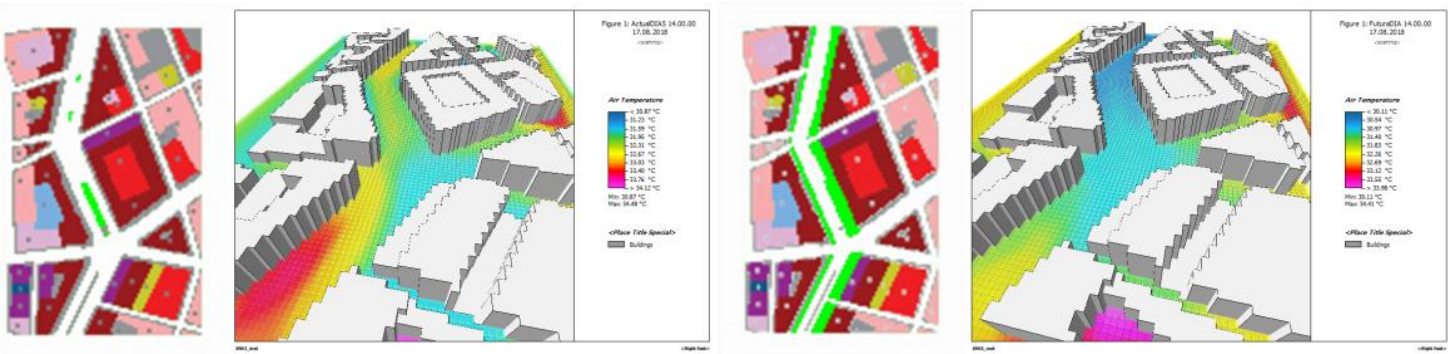

Fuente: Elaboración propia.

Los datos finales fueron:

- Descenso de temperatura de aire diurna a nivel peatonal $(1,5 \mathrm{mt})$ de $2^{\circ} \mathrm{C}$ (de $32 / 33^{\circ} \mathrm{C}$ a $30 / 31^{\circ} \mathrm{C}$ ) y nocturna de $1^{\circ} \mathrm{C}$ (de $26,3 / 27^{\circ}$ a $25,5 / 26.55^{\circ} \mathrm{C}$ ).

- Disminución de la velocidad del viento entre un 10 y un $20 \%$ en horarios diurnos y nocturnos.

Figura 13. Temperatura de aire diurna y velocidad de viento. 1:: Existencias; 20: Proyecto

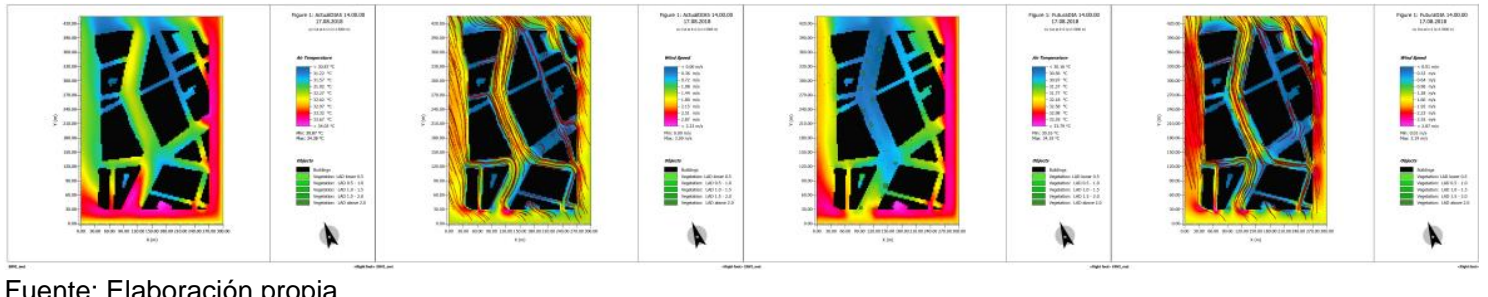

Fuente: Elaboración propia.

- Disminución de la temperatura media radiante en $20^{\circ} \mathrm{C}$ (de $62 / 65^{\circ} \mathrm{C}$ a $40 / 47^{\circ} \mathrm{C}$ ).

- Disminución de la temperatura de superficie en $15^{\circ} \mathrm{C}$ (de $41 / 48^{\circ} \mathrm{C}$ a $23 / 34^{\circ} \mathrm{C}$ ).

- Amento de la humedad relativa a nivel peatonal (1,5mt) de 44/48\% a 48/55\%.

Figura 14. Sky View Factor y Temperatura de superficie. 1ㅇ: Existencias; 20: Proyecto

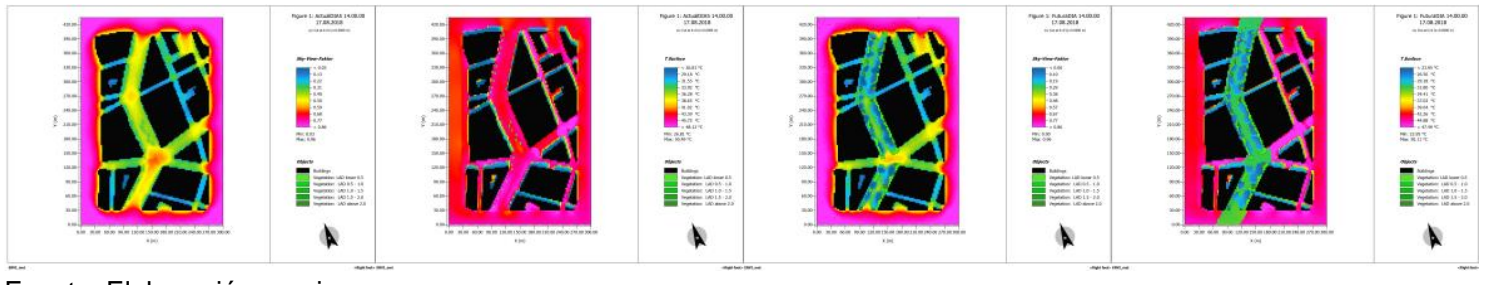

Fuente: Elaboración propia.

- Disminución de un $60 \%$ de exposición al sol (sky view factor) en verano, pero mantiene los valores en invierno debido a la vegetación caducifolia.

- Amento del albedo en toda el área de proyecto.

- Aumento del confort térmico en toda el área de proyecto y disminución del porcentaje de personas bajo condiciones climáticas insatisfactorias (PMV y PPD).

De esta forma queda demostrada la generación de un efecto de isla local de frio, donde las capas superiores, de aire frio, consiguen alcanzar el nivel peatonal. 


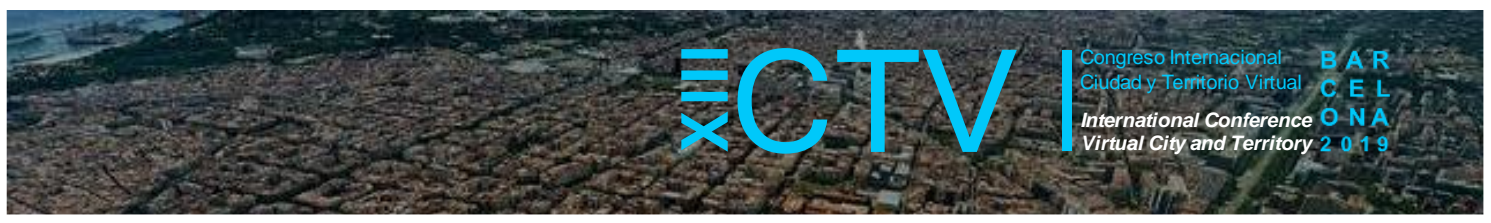

Figura 15. Temperatura de aire en sección. 1ㅇ: Existencias; 2ㅇ: Proyecto

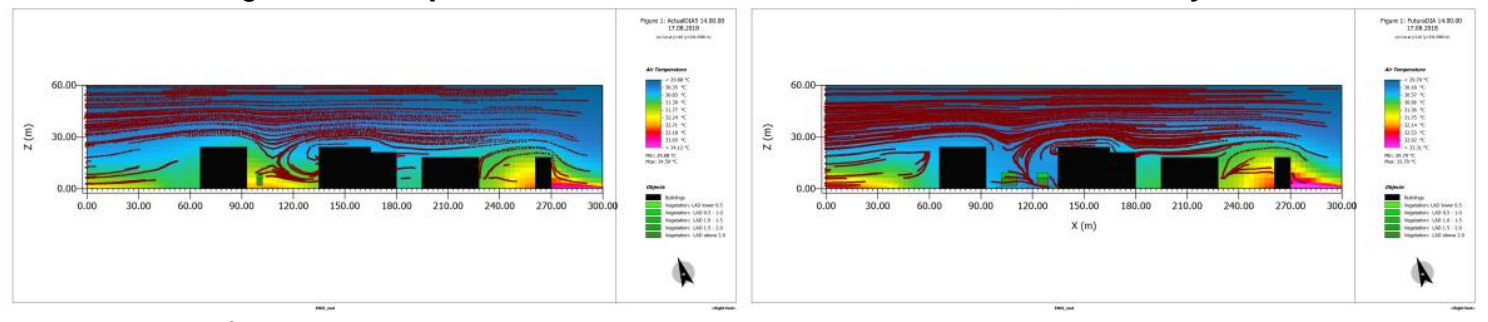

Fuente: Elaboración propia.

\section{Conclusiones}

Es necesario migrar hacia una planificación centrada en la naturaleza y la inclusión de las cuestiones climáticas en la práctica urbana para poder preparar a las ciudades para los escenarios futuros que tendremos por los efectos del cambio climático y la isla de calor urbana. Además, las simulaciones climáticas son una gran herramienta para poder conocer la magnitud de beneficios climáticos de un proyecto y prevenir posibles desventajas antes de intervenir en el territorio.

Agradecimientos: Este artículo ha sido desarrollado como Tesis Final del Master en Planificación Urbana y Sostenibilidad en la Universitat Politécnica de Catalunya y el Centro de Políticas de Suelo y Valoraciones, CPSV, con la tutoría del Doctor, arquitecto, Josep Roca Cladera y la arquitecta, M.Sc., Blanca Arellano Ramos.

\section{Bibliografía}

AEMET. Guía Resumida del Clima en España 1981-2010 de Agencia Estatal de Meteorología. Visor web de Infraestructura de Dades Espacials de les Illes Balears (IDEIB), Servei d'Informació Territorial de les Illes Balears (SITIBSA) del Govern de les Illes Balears.

AEMET Proyecciones climáticas para el siglo XXI. Agencia Estatal de Meteorología.

Ajuntament de Palma. (2019). L'Estratègia de model de ciutat. Revisió del Pla General de Palma. Área de Modelo de Ciudad.

Ajuntament de Palma de Mallorca. (2005). Mapa estratégico de ruido de la aglomeración de Palma de Mallorca.

Ajuntament de Palma de Mallorca. (2014). Plan de Movilidad Urbana Sostenible de Palma de Mallorca, PMUS. Recuperado de http://www.mobipalma.mobi/wpcontent/uploads/2017/06/PMUS Palma WEB ES.pdf

Ajuntament de Palma de Mallorca. Institut Municipal d'Innovació de Palma. (septiembre 2018). Carrerer municipal de Palma de Mallorca.

Boletin Oficial del Estado Español. (19 de febrero de 2016). Orden FOM/273/2016, aprobación de Norma 3.1-IC Trazado, de la Instrucción de Carreteras. BOIB. N55-Sec.1-Pag.17657. BOEA-2016-2217

Consell de Mallorca. (noviembre 2009). Pla Director Sectorial de Carreteres (Illa de Mallorca) Anexo 2. 


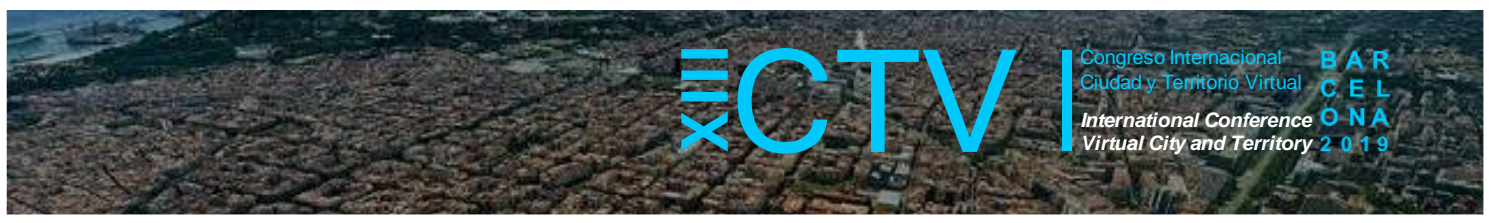

Consell de Mallorca. (2011). Infraestructura de Dades Espacials de Mallorca (IDE). Departament d'Urbanisme i Territori. Àrees de desenvolupament urbà, categories de sòl rústic i àrees de protecció territorial de carreteres i de costa del Pla territorial de Mallorca. Aprovat definitivament el 13/12/2004. Inclou la modificació núm. 1 aprovada el 3/6/2010 i la modificació núm. 2 aprovada el 13/1/2011.

Consell de Mallorca. (2017). PECMa Pla Director Sectorial d'Equipaments Comercials de Mallorca. Documento de Aprobación Inicial.

Consell de Mallorca. (2017). PECMa Pla Director Sectorial d'Equipaments Comercials de Mallorca. Documento de Evaluación ambiental estratégico. 2017

Consell de Mallorca. Direcció Insular de Carreteres. (2017). Mapa estacions aforaments IMD (Intensitat Mitjana Diària de Vehicles) 2017.

Consell de Mallorca. (2017). Memoria del Documento de Aprobación Inicial del Plan Director Sectorial de Equipamientos Comerciales de Mallorca (PECMa).

Consell de Mallorca. (julio 2018). Memoria justificativa. Documento de aprovación inicial. PIAT (Plan de Intervención de Ámbitos Turísticos de la Isla de Mallorca).

GOIB. Conselleria territori, energia i mobilitat. (2018). Presentación oficial del Resum aprovació Inicial. 20/06/2018. Pla Director Sectorial de Mobilitat de les Illes Balears 2019-2026.

Jorda, G. (septiembre 2017). et al. Proyecciones de clima regional marino sobre España. CLIVAR Exchanges núm. 73.

Junta Palma XXI. (junio 2016). La Ciudad Invadida. 1979-2015.

Mateu, J. et al. (mayo 2017). Mallorca y sus dinámicas metropolitanas: proximidad y movilidad cotidiana en una isla-ciudad. Revista EURE, Vol. 43, № 129.

Roca, J. et al (2011). Estructura urbana, policentrismo y sprawl: los ejemplos de Madrid y Barcelona. Ciudad y territorio: Estudios territoriales, ISSN 1133-4762, № 168, 2011, págs. 299321.

Ministerio para la Transición Ecológica. (abril 2019). Observatorio de la Movilidad Metropolitana. Informe 2017. Centro de Investigación del Transporte de la Universidad Politécnica de Madrid. Madrid.

Portal estadístico del Institut d'Estadística de les Illes Balears (IBESTAT).

Seguí Pons, J.M. et al. (2016). Los sistemas de bicicleta pública y la movilidad urbana sostenible. Un análisis en la ciudad de Palma (Mallorca, Islas Baleares). Departament de Geografía. Universitat de les Illes Balears. Boletin de la Asociación de Geógrafos Españoles. N71. 2016. 